\title{
Polyprenol from the Whole Plants of Leucaena leucocephala
}

\author{
Chung-Yi Chen*, Yau-Der Wang \\ School of Medical and Heath Science, The Fooyin University, Ta-Liao, Kaohuing, Taiwan, China. \\ Email: xx377@mail.fy.edu.tw
}

Received January $14^{\text {th }}, 2010$; revised February $24^{\text {th }}, 2010$; accepted February $25^{\text {th }}, 2010$.

\begin{abstract}
Ficaprenol-11 (polyprenol) (1), squalene (2), lupeol (3), $\beta$-sitostenone (4), trans-coumaric acid (5), cis-coumaric acid (6) pheophytin-a (7), pheophorbide a methyl ester (8), methyl-132-hydroxy-(132-S)- pheophorbide-b (9) and aristophyll-C (10) were isolated from the whole plants of Leucaena leucocephala (Leguminosae). Among them, $\mathbf{1}$ and $\mathbf{2}$ was found for the first time from this species. The structure of these compounds were characterized and identified by spectra analyses.
\end{abstract}

Keywords: Polyprenol, Leucaena leucocephala, Leguminosae

Leucaena leucocephala (Leguminosae) is a small, leguminous and native to tropical America, now widely distributed in southern Asia and neighboring islands [1]. This plant's reproductive capacity is extremely strong. If can henceforth the plant separate the effective component, applies, will be able to reduce it to the environment threat. Previous studies have show that the extract of L. leucocephala was found to exhibit various pharmacological effects [2-8], L. leucocephala was chosen for further phytochemical investigation. The $\mathrm{MeOH}$ extract of its plants were subjected to solvent partitioning and chromatographic separation to afford 10 pure substances. The chemical constituents in the plants of $L$. leucocephala were separated with column chromatography.

Investigation on the $\mathrm{MeOH}$ extract of the plants has led to the isolation of 10 compounds, one polyprenol: ficaprenol-11 (1) (Figure 1) [9]; two terpenoids: squalene (2) (Figure 2) [10] and lupeol (3) [11]; one steroid: $\beta$-sitostenone (4) [12]; two benzenoidș: transcoumaric acid (5) and cis-coumaric acid (6) [13]; and four chlorophylls: pheophytin-a (7) [14], pheophorbide a

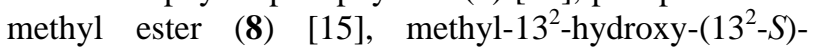
pheophorbide-b (9) [16] and aristophyll-C (10) [17]. These compounds were obtained and characterized by the comparison of their physical and spectral data (UV, IR, NMR and MS) with values obtained in the literature. Among them, 1 (Figure 1) and 2 (Figure 2) was found for the first time from this species.

The specimen of $L$. leucocephala was collected from Kenting National Park, Pingtung County, Taiwan in May, 2009. A voucher specimen was characterized by Dr. Jin-Cheng Huang of Department of Forest Products Science and Furniture Engineering, National Chiayi Univer- sity, Chiayi, Taiwan and deposited in the School of Medical and Health Sciences, Fooyin University, Kaohsiung County, Taiwan. The air-dried green beans of $L$. leucocephala $(5.0 \mathrm{~kg})$ were extracted with $\mathrm{MeOH}(80 \mathrm{~L}$ $\mathrm{x} 6$ ) at room temperature and the $\mathrm{MeOH}$ extract (132.5 g) was obtained upon concentration under reduced pressure. The $\mathrm{MeOH}$ extract was chromatographed over silica gel using $n$-hexane/acetone as eluent to produce 10 fractions. Part of fraction 1 (8.24 g) was subjected to Si gel chromatography by eluting with $n$-hexane/acetone (50:1), then enriched with acetone to furnish 7 fractions (1-1 1-7). Fraction 1-4 (2.17 g) was re-subjected to Si gel chromatography, eluting with $n$-hexane/Acetone (40:1) to obtain -sitostenone (4) (9 mg, 0.0068\%). Part of fraction 2 ( $2.67 \mathrm{~g})$ was subjected to Si gel chromatography by eluting with $n$-hexane/acetone (50:1) to obtain ficaprenol-11 (1) (Figure 1) (21 mg, 0.0158\%). Part of fraction 3 (6.77 g) was subjected to Si gel chromatography by eluting with $n$-hexane/acetone (8:1), then enriched with acetone to furnish 5 fractions (3-1 3-5). Fraction 3-3 (1.33 g) was further purified by another silica gel column using $n$-hexane/acetone to obtain squalene (2) (Figure 2) (5 mg, 0.0038\%) and lupeol (3) (24 mg, $0.0181 \%)$. Part of fraction 5 (7.42 g) was subjected to Si gel chromatography by eluting with $n$-hexane/acetone (8:1) to obtain pheophorbide a methyl ester (8) $(12 \mathrm{mg}$, $0.0091 \%)$. Part of fraction 6 (5.31 g) was subjected to Si gel chromatography by eluting with $n$-hexane/acetone (8:1) to obtain methyl-132-hydroxy-(132-S)-pheophorbide-b (9) (6 mg, 0.0045\%). Part of fraction 8 (4.91 g) was subjected to Si gel chromatography by eluting with $n$-hexane/acetone (5:1) to obtain pheophytin-a (7) (8 mg, $0.0060 \%)$. 


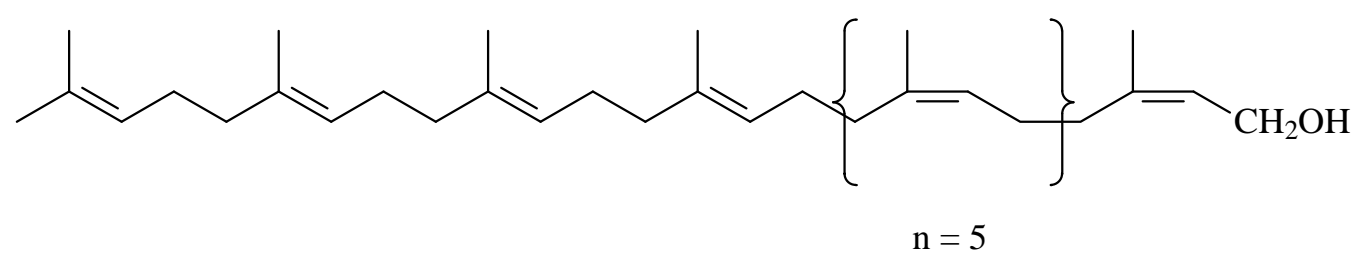

1

Figure 1. Chemical structure of Ficaprenol-11 (1)<smiles>CC(C)=CCC/C(C)=C/CC/C(C)=C/CC/C=C(\C)CC/C=C(\C)CCC=C(C)C</smiles>

2

Figure 2. Chemical structure of Squalene (2)

The air-dried leaves of $L$. leucocephala (5.8 kg) were extracted with $\mathrm{MeOH}(80 \mathrm{~L} \times 6)$ at room temperature and the $\mathrm{MeOH}$ extract (143.5 g) was obtained upon concentration under reduced pressure. The $\mathrm{MeOH}$ extract was chromatographed over silica gel using $n$-hexane/acetone as eluent to produce 8 fractions. Part of fraction 5 (9.22 g) was subjected to Si gel chromatography by eluting with $n$-hexane/acetone (8:1) to obtain aristophyll-C (10) (13 mg, $0.0091 \%)$. Part of fraction 8 (7.16 g) was subjected to Si gel chromatography by eluting with $n$-hexane/acetone $(5: 1)$ to obtain trans-coumaric acid (5) and ciscoumaric acid (6) mixture (5 mg, 0.0035\%) .

\section{Acknowledgment}

This investigation was supported by a grant from the National Science Council of Republic of China (NSC 97-2320-B-242-002-MY3).

\section{REFERENCES}

[1] A. M. Gamal-Eldeen, H. Amer, W. A. Helmy, R. M. Talaat, and H. Ragab, "Chemically-modified polysaccharide extract derived from Leucaena leucocephala alters Raw 264.7 murine macrophage functions,” International Immuno-pharmacology, Vol. 7, pp. 871-878, February 2007.

[2] A. J. Erickson, R. S. Ramsewak, A. J. Smucker, and M. G. Nair, "Nitrification Inhibitors from the roots of Leucaena leucocephala," Journal of Agricultural and Food Chemistry, Vol. 48, pp. 6174-6177, December 2000.

[3] T. D. Xuan, A. A. Elzaawely, F. Deba, M. Fukuta, and S. Tawata, "Mimosine in Leucaena leucocephala as a potent bio-herbicide," Agronomy for Sustainable Development, Vol. 26, pp. 89-97, April 2006.

[4] P. H. Kaufusi, L. S. Forsberg, P. Tittabutr, and D. Borthakur,
"Regulation of exopolysaccharide synthesis in rhizobium sp. strain TAL1145 involves an alternative sigma factor gene, rpoH2,” Microbiology, Vol. 150, pp. 3473-3482, October 2004.

[5] P. K. K. Yeung, F. T. W. Wong, and J. T. Y. Wong, "Mimosine, the allelochemical from the leguminous tree Leucaena leucocephala, selectively enhances cell prolixferation in dinoflagellates," Applied and Environmental Micro-biology, Vol. 68, pp. 5160-5163, October 2002.

[6] M. Soedarjo, and D. Borthakur, "Mimosine, a toxin produced by the tree-legume leucaena provides competition advantage to mimosine-degrading rhizobium strains," Soil Biology and Biochemistry, Vol. 30, pp. 1605-1613, October 1998.

[7] Y. Kamada, N. Oshiro, M. Miyagi, H. Oku, F. Hongo, and I. Chinen, "Osteopathy in broiler chicks fed toxic mimosine in Leucaena leucocephala," Bioscience Biotechnology and Biochemistry, Vol. 62, pp. 34-38, January 1998.

[8] I. M. Villasenor, R. M. T. Gajo, and R. C. Gonda, "Bioactivity studies on the alkaloid extracts from seeds of Leucaena leucocephala," Phytotherapy Research, Vol. 11, pp. 615-617, December 1998.

[9] I. L. Tsai, Y. F. Jeng, C. Y. Duh, and I. S. Chen, "Cytotoxic constituents from the leaves of Litsea akoensis," The Chinese Pharmaceutical Journal, Vol. 53, pp. 291-301, December 2001.

[10] K. Seki, T. Tomihari, K. Haga, and R. Kaneko, "Iristectorenes A and C-G, monocyclic triperpene esters from Iris tectorum,” Phytochemistry, Vol. 53, pp. 425-431, May 1994.

[11] C. Zhao, J. Shao, and X. Li, "Chemical constituents from fruits of Ailanthus altissima,” Zhongguo Zhong Yao Za Zhi, Vol. 34, pp. 2197-2199, September 2009.

[12] C. Y. Jiang, S. Z. Mu, B. Deng, Y. H. Ge, J. X. Zhang, and 
X. J. Hao, "Studies on the chemical constituents from Euphorbia chrysocoma," Zhong Yao Cai, Vol. 32, pp. 1390-1392, September 2009.

[13] C. J. Li, A. A. Ahmed, A. C. Arias, and T. J. Mabry, "Clerodane diterpenoids, long chain esters of coumaric acid and other compounds from Baccharis myrsinites," Phytochemistry, Vol. 45, pp. 571-574, June 1997.

[14] W. T. Li, H. W. Tsao, Y. Y. Chen, S. W. Cheng, and Y. C. Hsu, "A study on the photodynamic properties of chlorophyll derivatives using human hepatocellular carcinoma cells," Photochemical and Photobiological Sciences, Vol. 6, pp. 1341-1348, December 2007.

[15] M. C. Rho, M. Y. Chung, H. Y. Song, O. E. Kwon, S. W.
Lee, J. A. Baek, K. H. Jeune, K. Kim, H. S. Lee, and Y. K. Kim, "Pheophorbide A-methyl ester, Acyl-CoA: cholesterol acyltransferase inhibitor from Diospyros kaki," Archives of Pharmacal Research, Vol. 26, pp. 716-718, September 2003.

[16] M. S. Buchanane, T. Hashimoto, and Y. Asakawa, "Phytyl esters and phaeophytins from the hornwort Megaceros flagellaris,” Phytochemistry, Vol. 41, pp. 1373-1376, March 1996.

[17] Y. Y. Chan, Y. L. Leu, and T. S. Wu, "The constituents of the leaves of Aristolochia heterophylla Hemsl.," Chemical and Pharmaceutical Bulletin, Vol. 47, pp. 887-889, June 1999. 